\title{
Current trends in craniofacial distraction: A literature review
}

\author{
Farheen Fatima ${ }^{1, A-F}$, Waqar Jeelani ${ }^{2, A-F}$, Maheen Ahmed ${ }^{2, B-F}$ \\ ${ }^{1}$ Department of Orthodontics, Bahria University Medical and Dental College, Karachi, Pakistan \\ ${ }^{2}$ Department of Orthodontics, Bakhtawar Amin Medical and Dental College, Multan, Pakistan \\ A - research concept and design; $\mathrm{B}$ - collection and/or assembly of data; $\mathrm{C}$ - data analysis and interpretation; \\ $D$ - writing the article; $E$ - critical revision of the article; $F$ - final approval of the article
}

Address for correspondence

Waqar Jeelani

E-mail: wjeelani@gmail.com

Funding sources

None declared

Conflict of interest

None declared

Received on April 9, 2020

Reviewed on May 4, 2020

Accepted on May 18, 2020

Published online on December 31, 2020

Cite as

Fatima F, Jeelani W, Ahmed M. Current trends in craniofacial

distraction: A literature review. Dent Med Probl.

2020;57(4):441-448. doi:10.17219/dmp/122579

DOI

$10.17219 / \mathrm{dmp} / 122579$

Copyright

○) 2020 by Wroclaw Medical University

This is an article distributed under the terms of the

Creative Commons Attribution 3.0 Unported License (CC BY 3.0)

(https://creativecommons.org/licenses/by/3.0/)

\begin{abstract}
The techniques and procedures involved in craniofacial distraction are constantly evolving. The understanding of histological and biochemical response at the distraction site is now improved. The cascade of events in distraction osteogenesis (D0) differs significantly from the typical fracture healing, and a better knowledge about these events has helped us identify suitable candidates for D0, make appropriate modifications to the distraction protocols and minimize the risk of complications. Recent advances in the manufacturing techniques have also facilitated the availability of distractors of various shapes and designs, which are now changing the way different craniofacial defects are being treated. Small but rigid intraoral distractors now enable easy placement, are well tolerated by patients and allow for a long consolidation period. The introduction of newer approaches toward treatment, together with the simultaneous management of different craniofacial defects at multiple osteotomy sites and enhanced surgical accuracy with the help of digital imaging, have made treatment outcomes more predictable.
\end{abstract}

Key words: distraction, repair, lizarov technique, craniofacial syndrome, computer-assisted three dimensional imaging 


\section{Introduction}

Distraction osteogenesis (DO) is a well-established technique in the field of orthopedics, as it has been used for several decades for limb lengthening and the repair of long-bone defects. The standard protocol of DO is based on careful planning, with special attention being paid to the anatomy and blood supply of the osteotomy site, the patient's general health, and the design and mechanical properties of the distraction device.

The procedure is commenced with an osteotomy, followed by the insertion of a distractor. The osteotomy site is allowed to mature for a few days (the latency period); then, the distraction phase begins. The distractor is opened at a specific rate and rhythm so that the proximal and distal fragments of the bone start separating, leading to the mechanical induction of new bone formation between the bony surfaces at the osteotomy site. ${ }^{1}$ Once the desired lengthening of the bone is achieved, the process of distraction is stopped and the newly formed non-mineralized bone (callus) is allowed to mature for a period of several weeks to several months as part of the consolidation phase (Fig. 1). ${ }^{1}$

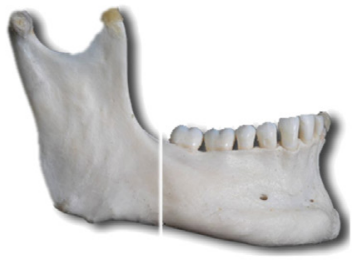

osteotomy and latency

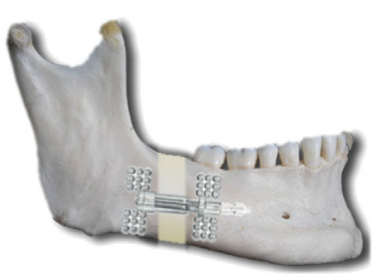

consolidation

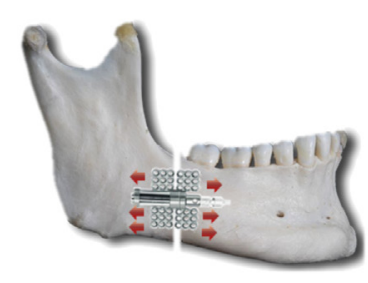

distraction

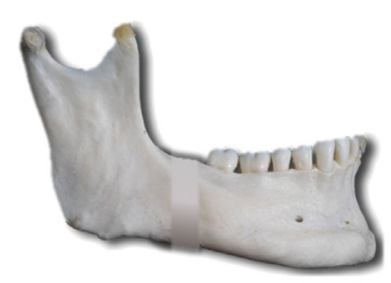

remodeling
Fig. 1. Phases of distraction osteogenesis (DO)

\section{Insights into the biological basis of craniofacial distraction}

Histologically, the latency phase of DO closely resembles typical fracture healing, which involves hematoma formation, local inflammatory response and the influx of mesenchymal stem cells. ${ }^{2,3}$ During rapid bone formation in the latency period, endochondral bone formation is observed along the periosteum. The region in the middle of the healing callus, regarded as a fibrous interzone (FIZ), is rich in fibroblasts, chondrocytes, and cells that have the morphological features of both chondroblasts and fibroblasts. ${ }^{4,5}$ The process of ossification starts from the area adjacent to the bone and FIZ ossifies the last. ${ }^{5,6}$
The predominant mechanism of bone formation is intramembranous, characterized by the formation of type-I collagen; however, a zone of endochondral bone formation is frequently observed. ${ }^{7-9}$ This process differs from the typical endochondral bone formation, as there is no capillary ingrowth in this cartilaginous matrix and the formation of type-II collagen by these chondroblast-like cells switches over to the production of type-I collagen. This process has been named as 'transchondroid bone formation.' ${ }^{10}$

The molecular expression during DO shows certain differences when compared to the molecular expression during fracture healing. Interleukin-6 (IL-6) concentration is increased not only during the initial inflammatory phase, but also when the distraction phase is started. Cho et al. showed that IL-6 could significantly enhance intramembranous ossification and had an overall anabolic effect during DO, contrary to its catabolic effect during fracture healing. ${ }^{11}$ The members of the transforming growth factor beta (TGF-ß) superfamily are other important mediators associated with DO, the expression of which is greater at the distracted osteotomy sites as compared to the nondistracted osteotomy or fracture sites. The expression of TGF- $B$ is positively correlated with the rate of distraction, which promotes new bone formation through osteoblastic proliferation. ${ }^{2,12}$ A similar pattern of expression has been described for bone morphogenic protein (BMP)-2 and BMP-4. ${ }^{13,14}$ In the absence of mechanical strain, they gradually disappear from the distraction site. Moreover, the addition of BMP-2 has been shown to reduce the latency period, and thus may be used to reduce the overall treatment time. ${ }^{15}$ Other important growth factors that play a role during different phases of DO include insulin-like growth factor-1 (IGF-1) and fibroblast growth factor (FGF)-2.16

Angiogenesis is an essential part of DO, in the absence of which non-bony union occurs. Angiogenesis during DO is more intense as compared to that during fracture healing, with studies reporting about a ten-fold increase in the blood flow during the distraction phase as compared to the normal blood flow. ${ }^{5}$ Similarly, since maximum bone formation occurs during the consolidation period, the maximum increase in the vessel volume has also been found during this period. The experimental inhibition of vascular endothelial growth factor (VEGF)-mediated angiogenesis also results in reduced osteogenesis activity. ${ }^{17}$ Although new vessel formation begins during activation, the maximum increase in the vessel volume occurs during consolidation, suggesting a link between angiogenesis and bone formation. ${ }^{17-19}$

\section{Evolution of distractor designs and techniques}

The evolution of distractor devices goes along with the evolution in the DO techniques. The concept of intraoral and extraoral distractor devices goes back to the era 
of McCarthy, when he used unidirectional extraoral distractors to lengthen the mandibles of patients suffering from congenital mandibular deficiencies in 1989.20,21 The following year, Guerrero reported the use of an intraoral toothborne distractor for mandibular symphyseal distraction. ${ }^{22}$

\section{Evolution of distractors for maxillomandibular distraction}

Generally, mandibular distractors can be categorized into extraoral and intraoral ones, intraoral distractors being tooth-borne, bone-borne or hybrid. On the other hand, extraoral distractors are always bone-borne (Fig. 2). These distractors allow vector adjustment during distraction. However, the 2 major drawbacks of these distraction devices were the uniplanar control of the vector and extraoral placement. A common type of extraoral distractor is a two-pin distractor, which offers the advantage of easy placement in situations where minimal bone mass is available, without compromising the quality of callus formation and bone healing. Soon after the introduction of unidirectional distractors, it was realized that most of the defects were three-dimensional (3D) and linear distractors failed to completely restore them. When distractors were applied to different parts of the ramus, angle and body of the mandible, the results were rarely ideal and never precise enough to achieve optimal dental occlusion. In 1995, Molina and Ortiz Monasterio ${ }^{23}$ demonstrated the use of bidirectional distractors by creating 2 osteotomy sites in the affected mandibles (Fig. 3), which further led to the development of multidirectional distraction devices, such as the ACE/Normed multidimensional distractor and the multi-vector mandibular distractor of McCarthy. ${ }^{24}$

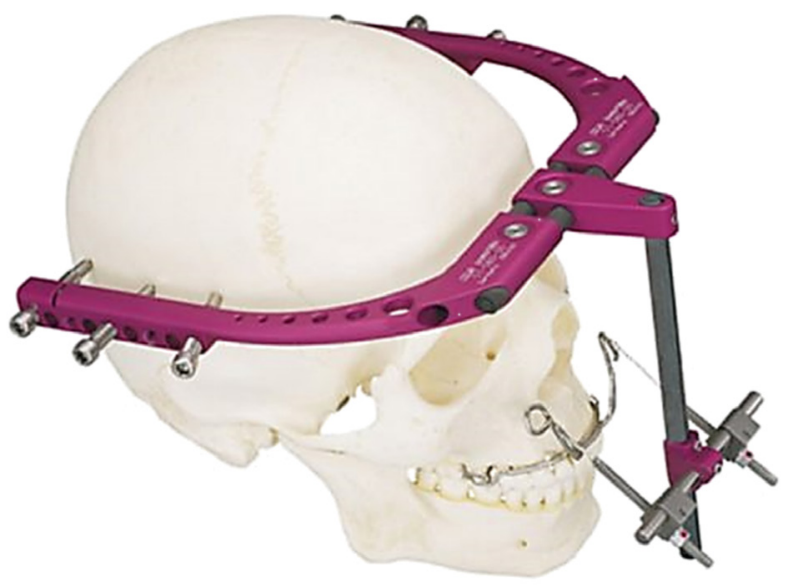

Fig. 2. Rigid external distractor

Another major leap in the evolution of distractors was the introduction of intraoral distractors, which were less conspicuous, easy to tolerate, socially acceptable, and free of the risk of facial scars. The realization of intraoral distractors was possible due to a significant reduction in the size of distractors

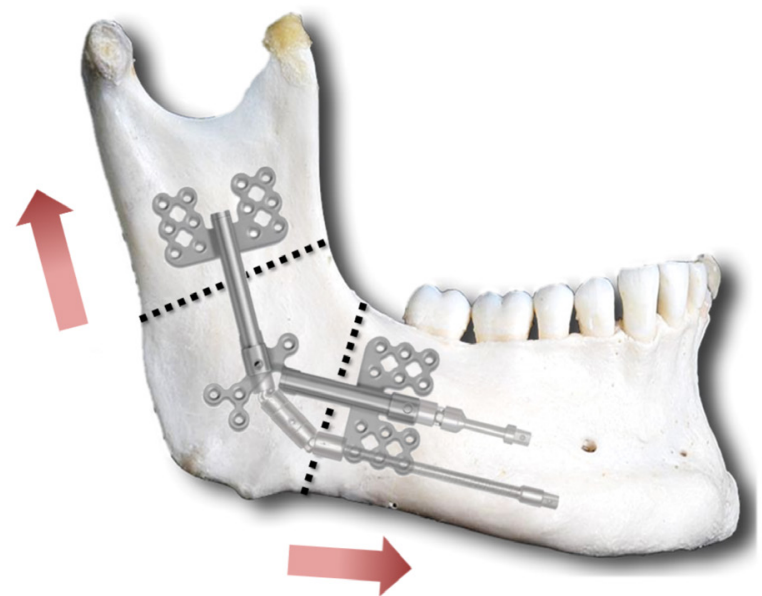

Fig. 3. Bidirectional distractor

and alteration in the distraction design. They were initially stock made, which meant they could be used for a specific bony location in any patient, as reported by Diner et al., ${ }^{25}$ or were universal in nature and could be placed on any site at the discretion of the surgeon, like the Dynaform Intraoral Distractor. ${ }^{26}$ A newer category of distractors were custom made and designed according to the needs of a specific patient. Razdolsky's tooth-borne and hybrid ROD devices are examples of distractors that allow the preprogrammed fabrication of the device along the predetermined axis of distraction according to the needs of the patient. . $^{27,28}$

The need for multidirectional or curvilinear distraction is often appreciated by oral and maxillofacial surgeons and orthodontists (Fig. 4). Multidirectional distractors are often large in size and need to be placed extraorally. A curvilinear distractor was described by Seldin ${ }^{29}$ in 1999 on animal models (Fig. 5). The curved design allows for the simultaneous lengthening of the mandibular body and ramus along a curved path, which is very similar to the pattern of natural growth of the mandible. ${ }^{30-32}$ In addition, this pattern of mandibular lengthening is favorable for the correction of an anterior open bite, a common iatrogenic condition during mandibular distraction. ${ }^{33}$

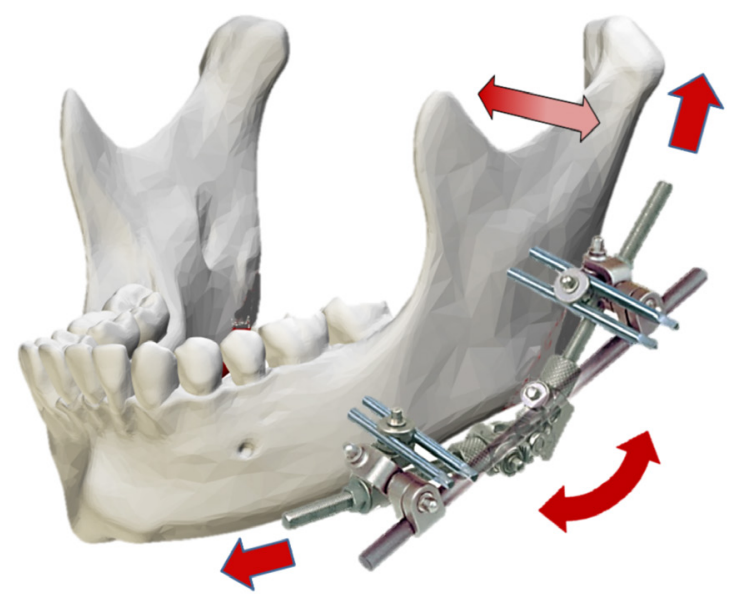

Fig. 4. Multidirectional distractor 


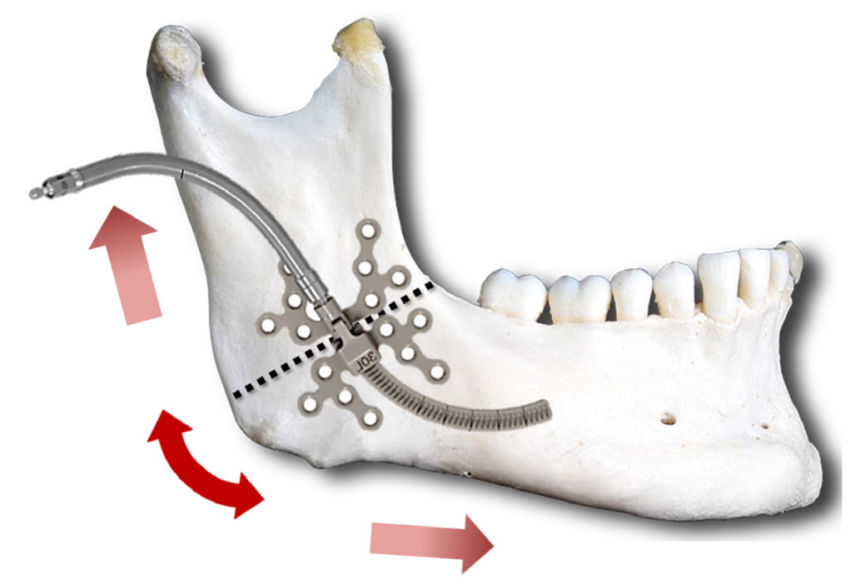

Fig. 5. Curvilinear distractor

A general concept that DO allows greater mid-facial advancement than the conventional orthognathic surgeries has been verified by a retrospective single-center study. ${ }^{34}$ Bone healing in the maxilla is relatively faster. Studies have shown that the traditional consolidation phase duration of 8 weeks or longer can be shortened without compromising stability. ${ }^{35,36}$ Though these devices have served the specialty well, there is still a need to develop an appliance system that would carry out automated and continuous distraction. It is not uncommon to find that many patients could not adhere to the distraction protocol - intentionally, due to the pain or discomfort associated with activation, or unintentionally, when they failed to comprehend or remember the distraction protocol. Recently, newer devices with hydraulic, motor-driven or spring-mediated mechanisms are being developed. The first reports on animal models are satisfactory, but significant improvement in the device design is needed, along with the need to include a distraction protocol that is compatible with human body, before these devices could be used for routine patient care..$^{37,38}$ Despite these deficiencies, it is expected that soon these appliances will become common, and thus will simplify the distraction process for patients and parents.

\section{Evolution of distractors for cranial and craniofacial defects}

In patients with differential dysmorphology involving the axial and sagittal planes, the en bloc movement using Le Fort III osteotomy may treat the position, but the axial dimension may remain untreated. The bipartition monobloc advancement using vertical osteotomy in the midline to pull the central face gives effective correction in midface concavity. ${ }^{36}$ Greater soft-tissue resistance laterally as compared to the center of the face during advancement results in a more convex shape of the sagittal facial profile. The separation of the zygoma after Le Fort III osteotomy at the zygomaticomaxillary suture also aids in differential advancement and the repositioning of the midface in the desired position relative to the corneal surface.

In patients with a shortened skull, DO allows correction over large distances, with the gradual movement and changes of the soft-tissue matrix. The contemporary distraction technique allows for the distraction of the cranium and skull base. The expansion of the anterior cranial fossa could also be performed, either in isolation or with the subcranial movement using the monobloc procedure, with the latter technique allowing for the simultaneous advancement of the inferior orbital rim, an increase in the dimension of the nasopharynx and overjet correction. The monobloc craniofacial advancement of the midface along with the anterior cranial vault is usually carried out at the age of 7-9 years, when the growth of the midface is almost complete. ${ }^{39}$ However, this procedure may involve a significant risk, as the sinus-brain barrier in the anterior cranial vault can be violated. This has resulted in a reduction in the frequency of using this procedure, which is usually limited to cases with circumorbital symmetric retrusion, in which the conventional staged advancement of the midface and the anterior cranial vault is not possible. ${ }^{40,41}$ Contrary to this approach, gradual expansion and advancement with DO minimizes the risk of the creation of dead space, and the subsequent morbidity associated with it. ${ }^{42}$ Though some authors have advocated the use of frontofacial monobloc distraction at the age of 1 year, the long-term results as well as the final esthetic and functional outcomes are yet to be investigated. ${ }^{43}$ In this regard, the use of early monobloc distraction is usually limited to life-threatening dysostosis, e.g., Pfeiffer type-II deformity. ${ }^{44}$

\section{Stimulation of bone repair}

To minimize the duration of bone repair during DO, various surgical and non-surgical strategies have been implemented. Non-surgical strategies include electric and electromagnetic stimulation, injecting growth hormones, cytokines and BMPs, and the use of low-level laser therapy (LLLT) and low-intensity pulse ultrasound (LIPUS).

The acceleration of bone repair and the modification of the period of inflammation with biological stimulation can be achieved by means of lasers. ${ }^{45-48}$ Low-level laser therapy was used in the past for the treatment of unhealed ulcers. ${ }^{49}$ It promotes osteoblastic activity during bone repair, which enhances the rate of bone healing. ${ }^{50}$ The factors affecting the laser dose may result in variations in the effectiveness of LLLT. These include power output and the duration of the applied therapy. The doses recommended by various studies vary from $10-112.5 \mathrm{~J} / \mathrm{cm}^{251-53}$ to $0.03-3 \mathrm{~J} / \mathrm{cm}^{2} \cdot{ }^{54-56}$ Another important criterion that affects the effectiveness of the therapy is the type of the target tissue, as this may result in variations in the depth 
of penetration. Mucosa is more susceptible to penetration as compared to fat and muscle tissues. Depending on the dose, the therapy may cause biostimulation or bioinhibition. ${ }^{57,58}$ Therefore, low doses $\left(3-5 \mathrm{~J} / \mathrm{cm}^{2}\right)$ are recommended rather than high doses $\left(50-100 \mathrm{~J} / \mathrm{cm}^{2}\right)$ to prevent the destructive effect. ${ }^{59}$

Ultrasound therapy produces micromechanical vibrations similar to physiological stress. The piezoelectric and angiogenic effects of ultrasound on bone apparently produce the therapeutic effect the therapy. ${ }^{60}$ The application of ultrasound has been reported in mandibular fractures in rabbits. ${ }^{61}$ Harris treated mandibular osteoradionecrosis with ultrasound in humans. ${ }^{62}$ An increased healing ratio of $88 \%$ has been reported when using ultrasound with the conventional therapy in 1,317 fracture cases in human subjects. ${ }^{63}$ With the application of LIPUS for $20 \mathrm{~min} /$ day, following DO for 10 days to lengthen the right tibia of rabbits, improved bone mineral density (BMD) at callus with increased stiffness and fracture strength have been observed. ${ }^{61}$ The application of $20-50 \mathrm{~mW} / \mathrm{cm}^{2}$ LIPUS results in a rise in tissue temperature $<1^{\circ} \mathrm{C}$. This brings about significant changes during bone formation and in the amount of enzymes. ${ }^{64,65}$ The tissue changes include a decrease in edema through the stimulation of mast cells. ${ }^{66}$ Furthermore, an increase in the adhesion of leukocytes to endothelium during the inflammation period causes the increased release of macrophages, fibroblasts and VEGF, and the stimulation of collagen synthesis from fibroblasts during the healing phase has been reported in various studies. ${ }^{67-70}$ Increased BMD was reported in a study conducted on dogs, which received $40 \mathrm{~mW} / \mathrm{cm}^{2}$ LIPUS for $20 \mathrm{~min} /$ day during the distraction phase at a 2-week interval. ${ }^{71}$

Both LLLT and LIPUS have been reported to be safe and non-invasive to improve the outcome of the DO treatment. ${ }^{72}$ Kocyigit et al. investigated the effects of ultrasound stimulation (LIPUS) and laser therapy (LLLT) on the BMD of the bone formed during DO with the use of dual energy X-ray absorptiometry. ${ }^{72}$ Both methods showed improvement in healing after DO and greater BMD in the exposed groups (LIPUS or LLLT) as compared to the controls. ${ }^{72}$

To improve the process of healing during and after distraction, several novel techniques are being implemented. A recent study investigated the effect of stem cells from human exfoliated deciduous teeth (SHED) on healing after DO. ${ }^{73}$ The results were quite promising, denoting significantly greater bone formation in the SHED-transplanted groups, thus improving the quality of union and the speed of bone maturation. ${ }^{73}$

Scientists are trying to explore the effects of different growth factors and biochemical mediators on DO. The role of BMPs and FGFs has long been documented. Recently, the positive effects of recombinant human erythropoietin (rhEPO) and platelet-rich plasma (PRP) have also been documented. ${ }^{74,75}$
Recombinant human erythropoietin has been shown to increase the number of osteoblasts and blood vessels, and reduce the number of osteoclasts, leading to a larger area of bone formation. ${ }^{75}$

These innovations in the science of DO can have significant clinical implication in the future. These methods may help reduce the latency and consolidation periods, improve bone strength after DO, improve the vascularity of tissues, and reduce the risk of complications.

\section{Virtual surgical simulation and three-dimensional distraction osteogenesis}

The process of DO in the craniofacial region consists of both linear and rotational movements as opposed to only linear movements in the case of epiphyseal lengthening. This is because of the morphology of the structures present in the head and the neck region. The vector produced by the distraction device is based on its position in relation to the surrounding bony structures. ${ }^{76}$

Hence, for advances the desired movement, the careful planning of the osteotomy cuts and the accurate placement of the device are fundamental. Innovations in 3D imaging techniques in the current era have enabled the accurate visualization of the craniofacial structures in all 3 planes of space. ${ }^{77}$

Recent advances in the virtual planning software have overcome some limitations, including achieving the desirable occlusal, functional and esthetic outcomes of two-dimensional (2D)-based DO. Intraoral distractors can produce movement only in a single direction; the accurate vector is dependent on the position of the device. Furthermore, intraoral devices are indicated for smaller defects, which make their placement more challenging due to a limited working field. The accurate placement and positioning of the device becomes even more important with intraoral distractors. ${ }^{78}$

Hence, the accurate transfer of the surgical procedure planned with the aid of 3D software is mandatory for achieving the desired results. Another advantage of the virtual planning software is that multiple treatment simulations can be performed to determine the most feasible plan in terms of risks, benefits and cost, which can be set for a specific patient. The surrounding structures, including the developing tooth germs, may be taken into consideration when planning the osteotomy cuts. With the introduction of rapid prototyping machines and $3 \mathrm{D}$ printers, the desired surgical stent and distractor templates can be computer-aided design/computer-aided manufacturing (CADCAM)-fabricated to further increase the accuracy of the planned surgical procedure. ${ }^{79,80}$ Lastly, distractors may be modified to adapt to the bony segments on models to reduce the intraoperative surgical time and inconvenience. 
The following are the basic guidelines for 3D-based DO and the fabrication of the surgical stent (Fig. 6):

- data acquisition: 3D imaging techniques, such as conebeam computed tomography (CBCT), computed tomography $(\mathrm{CT})$, magnetic resonance imaging (MRI), etc., have been used for data acquisition; these, along with the virtual models, are correlated on a common Cartesian system to construct a 3D model;

- data analysis and the determination of skeletal discrepancy: the exact skeletal discrepancy in all planes is computed using the 3D model; based on this, the exact amount and direction of movement of the bony segment is determined;

- determination of the position and angulation of the distractor: the vector is one of the significant factors for the achievement of the planned movement; this vector is determined by the position and angulation of the device on the bony segment, and the type of distractor used. With a unilateral distractor, the position and angulation becomes even more significant, as the distractor can be moved only in 1 plane. Various mathematical formulae can be used to calculate the required length and angle with respect to the bony bases by measuring the angle between the horizontal and vertical vectors ${ }^{81,82}$;

- treatment simulation: the osteotomy cuts are planned according the vector direction, taking into consideration the surrounding soft and hard structures. Usually, the osteotomy line is perpendicular to the vector distraction. The osteotomy cuts are simulated and the device is placed on the virtual models. If the movement is not satisfactory, an alternative plan may be simulated. An advantage of the virtual treatment planning software is the possibility of altering the position and angulation of the device until the desired result is achieved;

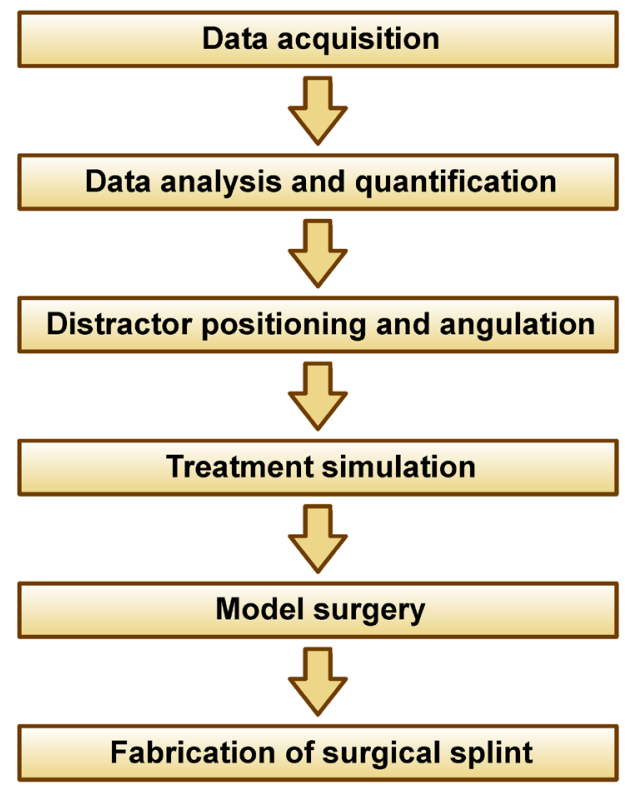

Fig. 6. Guidelines for three-dimensional (3D)-based DO
- model surgery and the fabrication of the surgical stent: various types of rapid prototyping, such as stereolithography and fused deposition modeling, may be used to fabricate models. ${ }^{83,84}$ The planned surgery is then performed on these models and a template distractor can be adapted to assess the feasibility of the treatment plan. Impressions of both the device and the bony surface are taken for the fabrication of the surgical stent. This stent is then used to transfer the planned surgery to the operating room.

\section{Discussion}

Recent advances have profoundly extended the scope of craniofacial DO. The incorporation of new diagnostic and treatment planning tools have improved the predictability of outcomes, providing the possibilities of using DO not only for deformity correction, but also in other situations. ${ }^{77}$ Osteodistraction may help the orthodontist to treat crowded dental arches with non-extraction therapy by improving the arch length and perimeter in severely crowded cases. ${ }^{22}$ Also, the regeneration of the alveolar bone for the placement of implants in patients with atrophic bone may be possible with this technique, which would be preferable to tissue reaction and rejection, as in the case of artificial bone used for the augmentation purpose. In the cases of ankylosis and discrepancy in vertical height, treatment with distraction may also help the tooth attain an esthetic and functional position.

The application of the concept of acceleration in the healing process has also helped in reducing the duration of the consolidation period, offering a great advantage to the clinician and patients, ${ }^{51,60}$ and distraction histogenesis occurring during DO allows for larger skeletal corrections with a lower risk of relapse due to soft tissue adaptation. Moreover, advances in the designs of distractors have improved the efficiency of treatment in achieving functional and esthetic results.

\section{Conclusions}

Distraction techniques have established themselves as a highly efficient and practical mode of treating craniofacial defects. Newer techniques are making distraction a routine procedure with a long-term follow-up now available in the published literature. Orthodontists need to keep themselves updated to the latest advances in the field of craniofacial distraction to be able to offer the most suitable treatment to their patients.

\section{ORCID iDs}

Farheen Fatima (1) https://orcid.org/0000-0001-5945-7185 Waqar Jeelani (1) https://orcid.org/0000-0003-0109-3117 Maheen Ahmed (1) https://orcid.org/0000-0003-0806-7739 


\section{References}

1. Cope JB, Samchukov ML, Cherkashin AM. Biologic basis of new bone formation under the influence of tension stress. In: Samchukov ML, Cope JB, Cherkashin AM, eds. Craniofacial Distraction Osteogenesis. St. Louis, USA: Mosby; 2001:21-36.

2. McCarthy JG, Stelnicki EJ, Mehrara BJ, Longaker MT. Distraction osteogenesis of the craniofacial skeleton. Plast Reconstr Surg. 2001;107(7):1812-1827. doi:10.1097/00006534-200106000-00029

3. Ai-Aql ZS, Alagl AS, Graves DT, Gerstenfeld LC, Einhorn TA. Molecular mechanisms controlling bone formation during fracture healing and distraction osteogenesis. J Dent Res. 2008;87(2):107-118. doi:10.1177/154405910808700215

4. Vauhkonen M, Peltonen J, Karaharju E, Aalto K, Alitalo I. Collagen synthesis and mineralization in the early phase of distraction bone healing. Bone Miner. 1990;10(3):171-181. doi:10.1016/0169-6009(90)90260-m

5. Aronson J. Temporal and spatial increases in blood flow during distraction osteogenesis. Clin Orthop Relat Res. 1994;(301):124-131.

6. Sato $M$, Yasui N, Nakase $T$, et al. Expression of bone matrix proteins mRNA during distraction osteogenesis. J Bone Miner Res. 1998;13(8):1221-1231. doi:10.1359/jbmr.1998.13.8.1221

7. Ilizarov GA. The tension-stress effect on the genesis and growth of tissues. Part II. The influence of the rate and frequency of distraction. Clin Orthop Relat Res. 1989;(239):263-285.

8. Ilizarov GA. The tension-stress effect on the genesis and growth of tissues. Part I. The influence of stability of fixation and soft-tissue preservation. Clin Orthop Relat Res. 1989;(238):249-281.

9. Karaharju EO, Aalto K, Kahri A, et al. Distraction bone healing. Clin Orthop Relat Res. 1993;(297):38-43.

10. Yasui N, Sato M, Ochi T, et al. Three modes of ossification during distraction osteogenesis in the rat. J Bone Joint Surg Br. 1997;79(5):824-830. doi:10.1302/0301-620x.79b5.7423

11. Cho TJ, Kim JA, Chung CY, et al. Expression and role of interleukin- 6 in distraction osteogenesis. Calcif Tissue Int. 2007;80(3):192-200. doi:10.1007/s00223-006-0240-y

12. Farhadieh RD, Dickinson $R, Y u$ Y, Gianoutsos MP, Walsh WR. The role of transforming growth factor-beta, insulin-like growth factor I, and basic fibroblast growth factor in distraction osteogenesis of the mandible. J Craniofac Surg. 1999;10(1):80-86. doi:10.1097/00001665-199901000-00016

13. Sato $M$, Ochi $T$, Nakase $T$, et al. Mechanical tension-stress induces expression of bone morphogenetic protein (BMP)-2 and BMP-4, but not BMP-6, BMP-7, and GDF-5 mRNA, during distraction osteogenesis. J Bone Miner Res. 1999;14(7):1084-1095. doi:10.1359/jbmr.1999.14.7.1084

14. Rauch F, Lauzier D, Croteau S, Travers R, Glorieux FH, Hamdy R. Temporal and spatial expression of bone morphogenetic protein-2, -4 , and -7 during distraction osteogenesis in rabbits. Bone. 2000;26(6):611-617. doi:10.1016/s8756-3282(00)00277-5

15. Yonezawa H, Harada K, Ikebe T, Shinohara M, Enomoto S. Effect of recombinant human bone morphogenetic protein-2 (rhBMP-2) on bone consolidation on distraction osteogenesis: A preliminary study in rabbit mandibles. J Craniomaxillofac Surg. 2006;34(5):270-276. doi:10.1016/j.jcms.2006.02.003

16. Tavakoli K, Yu Y, Shahidi S, Bonar F, Walsh WR, Poole MD. Expression of growth factors in the mandibular distraction zone: A sheep study. Br J Plast Surg. 1999;52(6):434-439. doi:10.1054/bjps.1999.3157

17. Bragdon B, Lybrand K, Gerstenfeld L. Overview of biological mechanisms and applications of three murine models of bone repair: Closed fracture with intramedullary fixation, distraction osteogenesis, and marrow ablation by reaming. Curr Protoc Mouse Biol. 2015;5(1):21-34. doi:10.1002/9780470942390.mo140166

18. Morgan EF, Hussein $\mathrm{Al}, \mathrm{Al}-\mathrm{Awadhi} \mathrm{BA}$, et al. Vascular development during distraction osteogenesis proceeds by sequential intramuscular arteriogenesis followed by intraosteal angiogenesis. Bone. 2012;51(3):535-545. doi:10.1016/j.bone.2012.05.008

19. Matsubara H, Hogan DE, Morgan EF, Mortolock DP, Einhorn TA, Gerstenfeld LC. Vascular tissues are a primary source of BMP2 expression during bone formation induced by distraction osteogenesis. Bone. 2012;51(1):168-180. doi:10.1016/j.bone.2012.02.017

20. McCarthy JG, Schreiber J, Karp N, Thorne CH, Grayson BH. Lengthening the human mandible by gradual distraction. Plast Reconstr Surg. 1992;89(1):1-8; discussion 9-10.

21. McCarthy JG. The role of distraction osteogenesis in the reconstruction of the mandible in unilateral craniofacial microsomia. Clin Plast Surg. 1994;21(4):625-631.
22. Guerrero CA. Surgical jaw expansion [in Spanish]. Rev Venez Ortod. 1990;7(1/2):48-50.

23. Molina F, Ortiz Monasterio F. Mandibular elongation and remodeling by distraction: A farewell to major osteotomies. Plast Reconstr Surg. 1995;96(4):825-840; discussion 841-842.

24. McCarthy JG. The development of various distraction devices. In: Abstract Book of the International Congress on Cranial and Facial Bone Distraction Processes. Paris, France; 1997:019.

25. Diner PA, Kollar EM, Viguier E, Maurin N, Vasquez MP. Intraoral submerged bidirectional device for mandibular distraction. In: Abstract Book of the International Congress on Cranial and Facial Bone Distraction Processes. Paris, France; 1997:017.

26. Bell WH, Gonzalez M, Samchukov ML, Guerreo CA. Intraoral widening and lengthening of the mandible by distraction osteogenesis. J Oral Maxillofac Surg. 1999;57(5):548-562;discussion 563. doi:10.1016/s0278-2391(99)90074-5

27. Razdolsky Y, Pensler JM, Dessner S. Skeletal distraction for mandibular lengthening with a completely intraoral tooth-borne distractor: A preliminary report. In: McNamara JA Jr., Trotman CA, eds. Distraction Osteogenesis and Tissue Engineering. Ann Arbor, USA: Center for Human Growth and Development, University of Michigan; 1998:117-140.

28. Razdolsky Y, Pensler JM. Skeletal distraction for mandibular lengthening with a completely intraoral tooth-borne distractor. In: Abstract Book of the International Congress on Cranial and Facial Bone Distraction Processes. Paris, France; 1997:050.

29. Seldin EB, Troulis MJ, Kaban LB. Evaluation of a semiburied, fixed trajectory, curvilinear, distraction device in an animal model. J Oral Maxillofac Surg. 1999;57(12):1442-1446; discussion 1447-1448. doi:10.1016/s0278-2391(99)90729-2

30. Moss ML, Salentijn L. The unitary logarithmic curve descriptive of human mandibular growth. Acta Anat (Basel). 1971;78(4):532-542. doi:10.1159/000143612

31. Ricketts RM. The biologic significance of the divine proportion and Fibonacci series. Am J Orthod. 1982;81(5):351-370. doi:10.1016/0002-9416(82)90073-2

32. Smartt JM Jr., Low DW, Bartlett SP. The pediatric mandible: I. A primer on growth and development. Plast Reconstr Surg. 2005;116(1):14e-23e. doi:10.1097/01.prs.0000169940.69315.9c

33. Schendel SA. Treatment of maxillomandibular deformities with internal curvilinear distraction. Ann Plast Surg. 2011;67(6):S1-S9. doi:10.1097/SAP.0b013e3182183599

34. Shetye PR, Davidson EH, Sorkin M, Grayson BH, McCarthy JG. Evaluation of three surgical techniques for advancement of the midface in growing children with syndromic craniosynostosis. Plast Reconstr Surg. 2010;126(3):982-994. doi:10.1097/PRS.0b013e3181e6051e

35. Hopper RA, Sandercoe G, Woo A, et al. Computed tomographic analysis of temporal maxillary stability and pterygomaxillary generate formation following pediatric Le Fort III distraction advancement. Plast Reconstr Surg. 2010;126(5):1665-1674. doi:10.1097/PRS.0b013e3181eff362

36. Burstein F, Soldanska M, Granger M, Berhane C, Schoemann M. Initial experience with a new intraoral midface distraction device. J Craniofac Surg. 2015;26(4):1224-1228. doi:10.1097/SCS.0000000000001728

37. Goldwaser BR, Papadaki ME, Kaban LB, Troulis MJ. Automated continuous mandibular distraction osteogenesis: Review of the literature. J Oral Maxillofac Surg. 2012;70(2):407-416. doi:10.1016/j.joms.2011.01.042

38. Hatefi S, Sh ME, Yihun $Y$, Mansouri R, Akhlaghi A. Continuous distraction osteogenesis device with MAAC controller for mandibular reconstruction applications. Biomed Eng Online. 2019;18(1):43. doi:10.1186/s12938-019-0655-0

39. Tessier $P$. The definitive plastic surgical treatment of the severe facial deformities of craniofacial dysostosis. Crouzon's and Apert's diseases. Plast Reconstr Surg. 1971;48(5):419-442. doi:10.1097/00006534-197111000-00002

40. Ortiz-Monasterio F, del Campo AF, Carrillo A. Advancement of the orbits and the midface in one piece, combined with frontal repositioning, for the correction of Crouzon's deformities. Plast Reconstr Surg. 1978;61(4):507-516. doi:10.1097/00006534-197804000-00003

41. Wolfe SA, Morrison G, Page LK, Berkowitz S. The monobloc frontofacial advancement: Do the pluses outweigh the minuses? Plast Reconstr Surg. 1993;91(6):977-987; discussion 988-989.

42. Bradley JP, Gabbay JS, Taub PJ, et al. Monobloc advancement by distraction osteogenesis decreases morbidity and relapse. Plast Reconstr Surg. 2006;118(7):1585-1597. doi:10.1097/01.prs.0000233010.15984.4d

43. Ahmad F, Cobb ARM, Mills C, Jones BM, Hayward RD, Dunaway DJ. Frontofacial monobloc distraction in the very young: A review of 12 consecutive cases. Plast Reconstr Surg. 2012;129(3):488e-497e. doi:10.1097/PRS.0b013e3182412820 
44. Polley JW, Figueroa AA, Charbel FT, Berkowitz R, Reisberg D, Cohen M. Monobloc craniomaxillofacial distraction osteogenesis in a newborn with severe craniofacial synostosis: A preliminary report. J Craniofac Surg. 1995;6(5):421-423. doi:10.1097/00001665-199509000-00022

45. Refai H, Radwan D, Hassanien N. Radiodensitometric assessment of the effect of pulsed electromagnetic field stimulation versus low intensity laser irradiation on mandibular fracture repair: A preliminary clinical trial. J Maxillofac Oral Surg. 2014;13(4):451-457. doi:10.1007/s12663-013-0551-2

46. Aronson J. Modulation of distraction osteogenesis in the aged rat by fibroblast growth factor. Clin Orthop Relat Res. 2004;(425):264-283. doi:10.1097/01.blo.0000138186.53426.f9

47. Tekin U, Tüz HH, Onder E, Ozkaynak O, Korkusuz P. Effects of alendronate on rate of distraction in rabbit mandibles. J Oral Maxillofac Surg. 2008;66(10):2042-2049. doi:10.1016/j.joms.2008.06.023

48. Pampu AA, Dolanmaz D, Tüz HH, Avunduk MC, Kişnişci RS. Histomorphometric evaluation of the effects of zoledronic acid on mandibular distraction osteogenesis in rabbits. J Oral Maxillofac Surg. 2008;66(5):905-910. doi:10.1016/j.joms.2007.12.004

49. Buchignani VC, Germano EJ, Dos Santos LM, et al. Effect of low-level laser therapy and zoledronic acid on bone repair process. Lasers Med Sci. 2019;34(6):1081-1088. doi:10.1007/s10103-019-02810-8

50. Barushka O, Yaakobi T, Oron U. Effect of low energy laser $(\mathrm{He}-\mathrm{Ne})$ irradiation on the process of bone repair in the rat tibia. Bone. 1995;16(1):47-55. doi:10.1016/s8756-3282(94)00006-9

51. Cerqueira A, Silveira RL, Oliveira MG, Sant'ana Filho M, Heitz C. Bone tissue microscopic findings related to the use of diode laser $(830 \mathrm{~nm})$ in ovine mandible submitted to distraction osteogenesis. Acta Cir Bras. 2007;22(2):92-97. doi:10.1590/s0102-86502007000200003

52. Blaya DS, Guimarães MB, Pozza DH, Blessmann Weber JB, de Oliveira MG. Histologic study of the effect of laser therapy on bone repair. J Contemp Dent Pract. 2008;9(6):41-48. doi:10.5005/jcdp-9-6-41

53. Lirani-Galvão AP, Jorgetti V, da Silva OL. Comparative study of how low-level laser therapy and low-intensity pulsed ultrasound affect bone repair in rats. Photomed Laser Surg. 2006;24(6):735-740. doi:10.1089/pho.2006.24.735

54. Garavello-Freitas I, Baranauskas V, Joazeiro PP, Padovani CR, Dal Pai-Silva M, da Cruz-Höfling MA. Low-power laser irradiation improves histomorphometrical parameters and bone matrix organization during tibia wound healing in rats. J Photochem Photobiol $B$. 2003;70(2):81-89. doi:10.1016/s1011-1344(03)00058-7

55. Pires Oliveira DAA, de Oliveira RF, Zangaro RA, Soares CP. Evaluation of low-level laser therapy of osteoblastic cells. Photomed Laser Surg. 2008;26(4):401-404. doi:10.1089/pho.2007.2101

56. Stein E, Koehn J, Sutter W, et al. Initial effects of low-level laser therapy on growth and differentiation of human osteoblast-like cells. Wien Klin Wochenschr. 2008;120(3-4):112-117. doi:10.1007/s00508-008-0932-6

57. Amid R, Kadkhodazadeh M, Ahsaie MG, Hakakzadeh A. Effect of low level laser therapy on proliferation and differentiation of the cells contributing in bone regeneration. J Lasers Med Sci. 2014;5(4):163-170.

58. de Freitas LF, Hamblin MR. Proposed mechanisms of photobiomodulation or low-level light therapy. IEEE J Sel Top Quantum Electron. 2016;22(3):7000417. doi:10.1109/JSTQE.2016.2561201

59. Huang YY, Chen ACH, Carroll JD, Hamblin MR. Biphasic dose response in low level light therapy. Dose Response. 2009;7(4):358-383. doi:10.2203/dose-response.09-027.Hamblin

60. Lou S, Lv H, Li Z, Tang P, Wang Y. Effect of low-intensity pulsed ultrasound on distraction osteogenesis: A systematic review and meta-analysis of randomized controlled trials. J Orthop Surg Res. 2018;13(1):205. doi:10.1186/s13018-018-0907-x

61. Fedotov SN, Minin EA, Borisov IN. Effect of local cooling and ultrasound on the reparative processes following mandibular fracture [in Russian]. Stomatologiia (Mosk). 1986;65(4):4-6.

62. Harris $M$. The conservative management of osteoradionecrosis of the mandible with ultrasound therapy. Br J Oral Maxillofac Surg. 1992;30(5):313-318. doi:10.1016/0266-4356(92)90181-h

63. Mayr E, Frankel V, Rüter A. Ultrasound - an alternative healing method for nonunions? Arch Orthop Trauma Surg. 2000;120(1-2):1-8. doi:10.1007/pl00021234

64. Chang WHS, Sun JS, Chang SP, Lin JC. Study of thermal effects of ultrasound stimulation on fracture healing. Bioelectromagnetics. 2002;23(4):256-263. doi:10.1002/bem.10009

65. Welgus HG, Jeffrey JJ, Eisen AZ, Roswit WT, Stricklin GP. Human skin fibroblast collagenase: Interaction with substrate and inhibitor. Coll Relat Res. 1985;5(2):167-179. doi:10.1016/s0174-173x(85)80038-8
66. Fyfe MC, Chahl LA. The effect of ultrasound on experimental oedema in rats. Ultrasound Med Biol. 1980;6(2):107-111. doi:10.1016/0301-5629(80)90038-1

67. Harrison A, Lin S, Pounder N, Mikuni-Takagaki Y. Mode \& mechanism of low intensity pulsed ultrasound (LIPUS) in fracture repair. Ultrasonics. 2016;70:45-52. doi:10.1016/j.ultras.2016.03.016

68. Doan N, Reher P, Meghji S, Harris M. In vitro effects of therapeutic ultrasound on cell proliferation, protein synthesis, and cytokine production by human fibroblasts, osteoblasts, and monocytes. J Oral Maxillofac Surg. 1999;57(4):409-419;discussion 420. doi:10.1016/s0278-2391(99)90281-1

69. Vavva MG, Grivas KN, Carlier A, et al. Effect of ultrasound on bone fracture healing: A computational bioregulatory model. Comput Biol Med. 2018;100:74-85. doi:10.1016/j.compbiomed.2018.06.024

70. Baron C, Guivier-Curien C, Nguyen VH, Naili S. Bone repair and ultrasound stimulation: An insight into the interaction of LIPUS with the bone callus through a multiscale computational study. J Acoust Soc Am. 2017;142(4):2600. doi:10.1121/1.5014516

71. Ding $Y, L i$ G, Zhang $X$, et al. Effect of low intensity pulsed ultrasound on bone formation during mandible distraction osteogenesis in a canine model - a preliminary study. J Oral Maxillofac Surg. 2009;67(11):2431-2439. doi:10.1016/j.joms.2009.05.441

72. Kocyigit ID, Coskunses FM, Pala E, Tugcu F, Onder E, Mocan A. A comparison of the low-level laser versus low intensity pulsed ultrasound on new bone formed through distraction osteogenesis. Photomed Laser Surg. 2012;30(8):438-443. doi:10.1089/pho.2012.3263

73. Alkaisi A, Ismail AR, Mutum SS, Rifin Ahmad ZA, Masudi S, Abd RazakNH. Transplantation of human dental pulp stem cells: Enhance bone consolidation in mandibular distraction osteogenesis. J Oral Maxillofac Surg. 2013;71(10):1758.e1-e13. doi:10.1016/j.joms.2013.05.016

74. Plachokova AS, Nikolidakis D, Mulder J, Jansen JA, Creugers NHJ. Effect of platelet-rich plasma on bone regeneration in dentistry: A systematic review. Clin Oral Implants Res. 2008;19(6):539-545. doi:10.1111/j.1600-0501.2008.01525.x

75. Mihmanli A, Dolanmaz D, Avunduk MC, Erdemli E. Effects of recombinant human erythropoietin on mandibular distraction osteogenesis. J Oral Maxillofac Surg. 2009;67(11):2337-2343. doi:10.1016/j.joms.2008.06.082

76. McCarthy JG, Grayson B, Williams JK, Turk A. Distraction of the mandible: The New York University experience. In: McCarthy JG, ed. Distraction of the Craniofacial Skeleton. New York, USA: Springer; 1999:80-203.

77. Hassfeld S, Mühling J. Computer assisted oral and maxillofacial surgery - a review and an assessment of technology. Int J Oral Maxillofac Surg. 2001;30(1):2-13. doi:10.1054/ijom.2000.0024

78. Tan A, Chai Y, Mooi W, et al. Computer-assisted surgery in therapeutic strategy distraction osteogenesis of hemifacial microsomia: Accuracy and predictability. J Craniomaxillofac Surg. 2019;47(2):204-218. doi:10.1016/j.jcms.2018.11.014

79. Paeng JY, Lee JH, Lee JH, Kim MJ. Condyle as the point of rotation for 3-D planning of distraction osteogenesis for hemifacial microsomia. J Craniomaxillofac Surg. 2007;35(2):91-102. doi:10.1016/j.jcms.2006.12.004

80. Scolozzi P, Herzog G. Computer-assisted virtual planning for surgical guide manufacturing and internal distractor adaptation in the management of midface hypoplasia in cleft patients. Cleft Palate Craniofac J. 2017;54(4):457-464. doi:10.1597/15-208

81. Badiali G, Cutolo F, Roncari A, Marchetti C, Bianchi A. Simulationguided navigation for vector control in pediatric mandibular distraction osteogenesis. J Craniomaxillofac Surg. 2017;45(6):969-980. doi:10.1016/j.jcms.2017.02.006

82. Grayson $\mathrm{BH}$, Santiago PE. Treatment planning and biomechanics of distraction osteogenesis from an orthodontic perspective. Semin Orthod. 1999;5(1):9-24. doi:10.1016/s1073-8746(99)80038-3

83. Pucci R, Priore P, Manganiello L, Cassoni A, Valentini V. Accuracy evaluation of virtual surgical planning (VSP) in orthognathic surgery: Comparison between CAD/CAM fabricated surgical splint and CAD/CAM cutting guides with PSI. J Oral Maxillofac Surg. 2019;77(9):E4-E5. doi:10.1016/j.joms.2019.06.020

84. Kim MJ, Seo J, Kim DK, Baek SH. Three-dimensional virtual-surgery simulation-assisted asymmetric bilateral mandibular distraction osteogenesis for a patient with bilateral condylar fractures. Am J Orthod Dentofacial Orthop. 2017;151(1):186-200. doi:10.1016/j.ajodo.2015.11.033 